\title{
X-ray Diffraction Topography - Investigation of Single Crystals Grown by the Czochralski Method
}

\author{
M. Lefeld-SosnowskA ${ }^{a}$ AND A. MAlinowsKa ${ }^{b, *}$ \\ ${ }^{a}$ Institute of Experimental Physics, University of Warsaw, Hoża 69, PL 00-681 Warsaw, Poland \\ ${ }^{b}$ Institute of Electronic Materials Technology, Wólczyńska 133, PL01-919 Warsaw, Poland
}

\begin{abstract}
X-ray diffraction topography is one of basic diagnostics tools serving for visualisation of single crystal lattice defects. Defects of various kinds can be observed. The present study is a review of topographic results obtained in the X-ray laboratory of the Institute of Experimental Physics, University of Warsaw, for three families of single crystals grown by the Czochralski method: (i) silicon ( $\mathrm{Si}$ ) and $\mathrm{Si}_{1-x} \mathrm{Ge}_{x}$, (ii) selected binary $\mathrm{REVO}_{4}$ oxides and (iii) selected ternary $\mathrm{ABCO}_{4}$ oxides. The effect of chemical composition, growth conditions and post growth thermal annealing on the defect appearing in crystals is discussed. Various defects are revealed: the growth dislocations (some early $\mathrm{Si}$ crystals), the composition-gradient-induced lattice deformation $\left(\mathrm{Si}_{1-x} \mathrm{Ge}_{x}\right.$, solid solutions $\mathrm{Ca}_{x} \mathrm{Sr}_{1-x} \mathrm{NdAlO}_{4}$ ), defects generated in $\mathrm{Si}$ after the post growth thermal processes, oriented elongated rod-like macro-defects tending to form networks within the crystal core, cellular structure in the outer shell $\left(\mathrm{SrLaGaO}_{4}\right)$, and variously developed block structure (in selected binary $\mathrm{REVO}_{4}$ crystals).
\end{abstract}

DOI: 10.12693/APhysPolA.124.360

PACS: 61.72.Ff

\section{Introduction}

Single crystals grown by the Czochralski method have been used in electronic technology for a long time. Successful applications require large crystals of a good crystallographic perfection. This requirement caused the development of the diagnostic methods, such as X-ray diffraction topography, which enabled to detect and characterize diverse crystal lattice defects for a large variety of Czochralski-grown crystals.

In X-ray diffraction topography, the intensity of the $\mathrm{X}$-ray beam, diffracted by a given family of crystal lattice planes, according to the Bragg law $2 d_{h k l} \sin \theta_{\mathrm{B}}=n \lambda$, is registered on a photographic plate as a two-dimensional map of the crystal. Analysis of the crystal image provides information on the real structure of the studied crystal.

Significant development of X-ray topography has been done by A.R. Lang, who has worked out the section topography and (later) the projection topography techniques [1-4]. The latter gives the possibility of recording the images of large crystal samples due to translation of the crystal and film against the primary beam, as it is schematically shown in Fig. 1a.

The section topograph is obtained by setting a given family of crystal lattice planes $h k l$ at the Bragg angle $\theta_{\mathrm{B}}$ (for $K_{\alpha_{1}}$ line of characteristic radiation) to the incoming X-ray beam. The beam is collimated by a slit $S_{1}$ and $S_{2}$ (Fig. 1a). The slit $S_{2}$ is very narrow (about $20-30 \mu \mathrm{m}$ ), which reduces the divergence of the beam to a smaller value than the difference between $\theta_{\mathrm{B}} K_{\alpha_{1}}$ and $\theta_{\mathrm{B}} K_{\alpha_{2}}$.

\footnotetext{
*corresponding author; e-mail: agnieszka.malinowska@itme.edu.pl
}

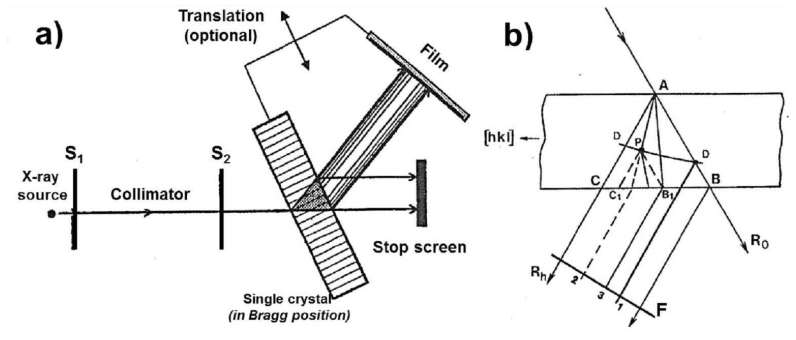

Fig. 1. (a) Schematic experimental setup for X-ray diffraction topography: section (stationary) or projection (with translation) mode. $S_{1}, S_{2}$ - slits. (b) Scheme of diffraction contrast formation in section topographs (schematically, in one diffraction plane). $R_{h}$ - diffracted beam; $R_{0}$ - refracted beam; ABC - Borrmann triangle; $\mathrm{D}$ - dislocation; $\mathrm{F}$ - photographic plate; 1 - direct image; 2 - dynamical image; 3 - intermediary image. According to [5].

As a result only the $K_{\alpha_{1}}$ line is diffracted by a crystal. The direct beam is eliminated by a stop screen, located behind the crystal. The diffracted beam is registered on a photographic plate (Fig. 1a).

The angular range of diffraction (for monochromatic, parallel incident wave and an ideal crystal structure) is limited to a few arc seconds. In a real crystal where the lattice planes are locally deformed or the distance $d_{h k l}$ varies, and as a result their inclination to the primary beam is slightly different as compared to domains of high structural perfection - the intensity of the diffracted beam is changed. In the topograph this change is observed as "diffraction contrast". These changes of diffracted beam intensity recorded on a photographic plate form the topogram, which is a map of diffracted beam intensity forming an image of the reflecting crystal. The degree of blackening depends on the $I_{h}$ 
value: if the diffracted beam intensity $I_{h}$ is lower than $I_{h}^{\mathrm{P}}$ (diffracted beam intensity for ideal crystal part) the observed contrast is brighter or white, if it is greater the contrast is darker or black.

The X-ray beam collimated by slits represents a spherical wave. Propagation of wave fields (according to the dynamical theory of the $\mathrm{X}$-ray diffraction for spherical waves [6-8]) is confined to the Borrmann triangle (ABC in Fig. 1b). The interference of wave fields results in maxima and minima of diffracted wave intensity, and in a topograph one can observe so called "Kato fringes".

When a defect appears in the Borrmann triangle, it disturbs the propagation of the wave fields and modifies their intensity. This results in changes of the film blackening and in the disturbance of the Kato fringe pattern, even at a relatively long distance from the defect.

The projection topograph, obtained by translation (see Fig. 1a) of the crystal and the film against the primary beam, gives a possibility to register the beam diffracted by a large sample. In the projection topographs, the registered intensity is integrated over the Borrmann triangle base. The fine interference structure of the diffraction image of defects is not always observed in projection topographs.

The diffraction contrast, caused by an isolated defect, has its origin in interaction of X-ray wave fields propagated in the crystal with distortion field of the defect. As a result of such interaction, the diffracted wave intensity can be modified, due to:

(a) the curvature of wave fields propagation directions (and, in a consequence, changes of wave fields absorption coefficients),

(b) creation of the new wave fields and interference of "newly created" wave fields with "normal" fields.

The types of contrast, observed in transmission section topographs are classified as "direct image", "dynamical image" and "intermediary image" [9-11].

The "direct image" arises for defects, situated on the way of waves, propagated in the forward direction, called the direct beam, which has the divergence higher than angular range of the reflection used. The part of the beam, which is not diffracted in the perfect crystal region, undergo diffraction by distorted lattice in the region of defect. The intensity of the diffracted beam is increased, and a black contrast is observed. The direct contrast dominates in projection topographs in the case of small $\mu d$ ( $\mu$ is the linear absorption coefficient, $\mathrm{d}$ is the sample thickness) values. In section topographs it arises for defects, situated near the primary beam direction, at the line $\mathrm{AB}$ of Borrmann triangle in Fig. 1b.

The "dynamic image" is formed when wave fields pass through the region of small gradient of crystal lattice distortion. The directions of wave fields propagation are changed, the paths are curved, and in consequence the intensities of diffracted waves at the crystal exit surface are changed (Fig. 1b).

The interaction of wave fields with the deformation field of high strain gradient (at the dislocation core) leads to decoupling of wave fields and creation of new ones at point $\mathrm{P}$, which is the apex of small Borrmann triangle $\mathrm{PB}_{1} \mathrm{C}_{1}$ (Fig. 1b). This phenomenon is described as "interbranch scattering". Interference of the "newly created" fields with the "normal ones" results in periodic changes of diffracted wave intensity what corresponds to "intermediary image" (point 2 on the film in Fig. 1b), superimposed on whole diffraction image of the defect.

Two phenomena: the curvature of wave fields paths and transmission of the energy of wave fields to the "newly created" fields by inter-branch scattering result in diminishing the amplitude of the diffracted wave at the crystal exit surface (point 3 in Fig. 1b). It can be said that the defect "casts a shadow" [9]. The image of a defect, observed on section topographs depends on: properties of the primary beam (wavelength, divergence), diffraction conditions (geometry of diffraction, reflection used), properties of the defect (as for instance a dislocation) and its orientation with respect to the reflecting plane and crystal surface, and its position in the crystal in depth and with respect to primary and diffracted beams $\left(R_{0}\right.$ and $R_{h}$ in the Borrmann triangle, Fig. $1 \mathrm{~b}$ ).

Interpretation of diffraction contrast, observed in topographs, can be done on the basis of dynamical theories of X-ray diffraction in deformed crystals developed by Penning and Polder [12, 13] and Kato [8, 14-16]. The theory of Takagi-Taupin [17-19] permits to calculate the distribution of the diffracted wave intensity at the crystal exit surface, registered on the film in a section topograph, what gives a possibility of numerical simulation of the diffraction picture.

Investigations of crystal lattice defects using Lang diffraction topography methods were conducted by many Laboratories. Among them, the X-ray Laboratory of the Institute of Experimental Physics in Warsaw University have undertaken investigations of single crystals by means of Lang topography methods. All investigated crystals were grown at the Institute of Electronic Materials Technology. Some examples of our results are shown in the article.

\section{Topography for as grown crystals}

\subsection{Czochralski grown silicon}

The projection topography permits to observe and analyze of defects of various types (for instance, dislocations, inclusions), their distribution and density. The diffraction image of a dislocation, found in a section topograph, contains three kinds of contrasts. By means of this technique one can study the dependence of the diffraction contrast on the position of the defect in the Borrmann triangle, on its orientation with respect to the diffracting lattice plane or on its depth in the crystal.

First silicon single crystals, grown by Czochralski method contained numerous dislocations. The dislocations in $\mathrm{Cz}-\mathrm{Si}$ crystals, grown with [111] oriented seed, were mainly laying in $\{111\}$ glide planes, inclined at an 
angle of $19.5^{\circ}$ to the growth axis. The appropriate sample surface orientation for dislocation observation was the lattice plane parallel to the growth axis. The investigations were therefore performed using the samples, cut out from as grown crystal, parallel to the (112) planes (assuming the [11]] crystallographic direction as growth axis). Moreover, the density of dislocations was not uniform, as it was indicated by selective chemical etching of the sample, cut out perpendicularly to the growth axis (Fig. 2a). It allowed to make a choice of place of low dislocation density.

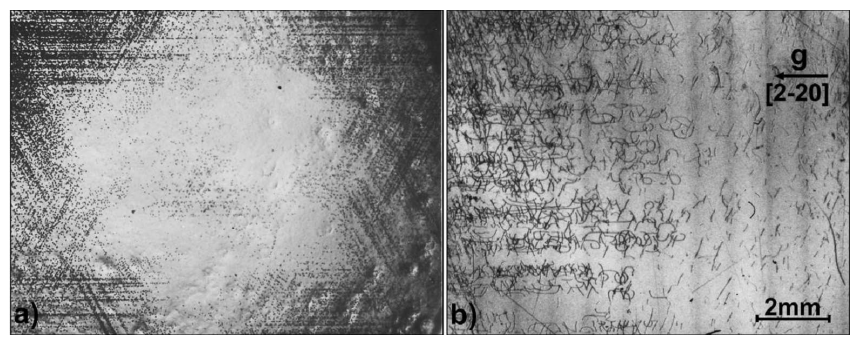

Fig. 2. $\mathrm{Cz}-\mathrm{Si}$ crystal grown in the [111] direction: (a) Image of the etched (11) $)$-oriented surface of the sample; (b) Fragment of the transmission projection topograph of the sample with the surface parallel to the

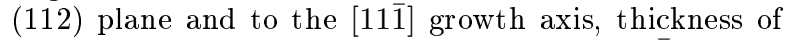
the sample $d=0.34 \mathrm{~mm}$, MoK $K_{\alpha_{1}}$ radiation, $2 \overline{2} 0$ reflection. $\boldsymbol{g}$ projection of the diffraction vector on the film. After [20].

Curvilinear dislocations were observed in $\mathrm{Cz}_{-}-\mathrm{Si}$ sample of (112) surface, cut out near the seed part of the crystal, grown in [11] $]$ direction (Fig. 2b). The straight-line dislocations, observed in $\mathrm{Cz}-\mathrm{Si}$ are shown in a projection topograph in Fig. 3a; a selected $60^{\circ}$ dislocation is marked by a frame. The changes of the diffraction contrast image for this dislocation situated at successive positions in the Borrmann triangle are shown in section topographs in Fig. 3b. Well developed interference structure of the dislocation image is demonstrated in the first (from left) section topograph, whereas in the last one can distinguish the "direct image".

Projection topographs of $\mathrm{Cz}-\mathrm{Si}$ crystal, containing, in particular, an isolated $60^{\circ}$ dislocation (A) and a group of $90^{\circ}$ dislocations (B) are shown in Fig. 4a,b.

Diffraction images of the dislocation (marked by $\mathrm{A}$ in Fig. 4), observed in section topographs taken with $1 \overline{1} 1$ reflection, show a very well developed "intermediary image" and its very distinct changes (Fig. 5a). For comparison in Fig. 5b one can see the series of the section topographs of this dislocation, obtained for the symmetric $1 \overline{3} 1$ reflection belonging to the same crystallographic zone as the $1 \overline{1} 1$ one. The Bragg angle for the $1 \overline{3} 1$ reflection is greater than for the $1 \overline{1} 1$ one, so the breadth of the section pattern is larger and consequently the Kato fringes are more distinct. A difference in total fringe numbers in the intermediary contrast observed in Fig. 5a and b is due to the different structure factors (and in consequence the different extinction length) of reflections. The perturba-

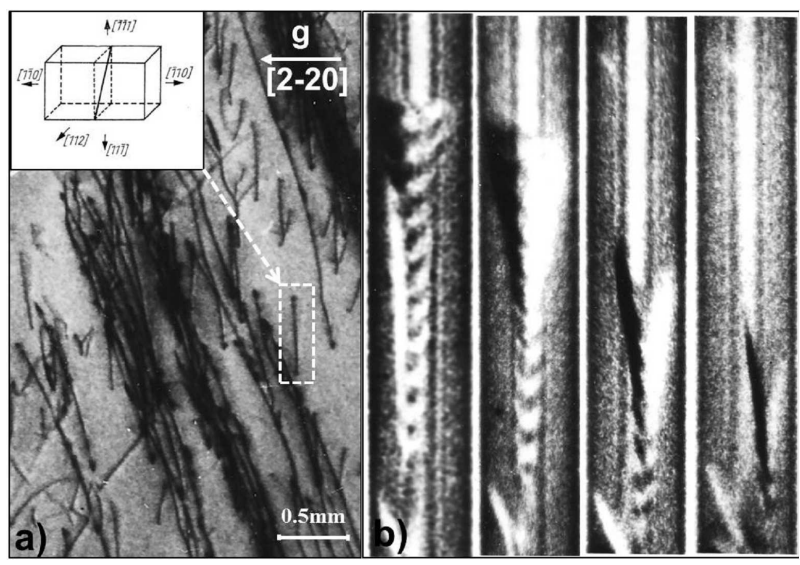

Fig. 3. X-ray transmission topographs of the (112)-oriented sample cut out from $\mathrm{Cz}-\mathrm{Si}$ crystal grown in the $[11 \overline{1}]$ direction. (a) projection topograph, the isolated "grown in" dislocation is marked by a frame; the diagrammatic position of the dislocation with respect to the sample surfaces is shown as an inset. (b) Section topographs of the region including the dislocation; the topographs were taken for successive dislocation positions in the Borrmann triangle; the translation of the crystal with respect to the incident beam were done by steps of $20 \mu \mathrm{m}$. $\boldsymbol{g}$ denotes projection of the diffraction vector on the film. Thickness of the sample was $d=0.46 \mathrm{~mm}$. The image was taken for $2 \overline{2} 0$ reflection, using $\operatorname{Mo} K_{\alpha_{1}}$ radiation. After [21].

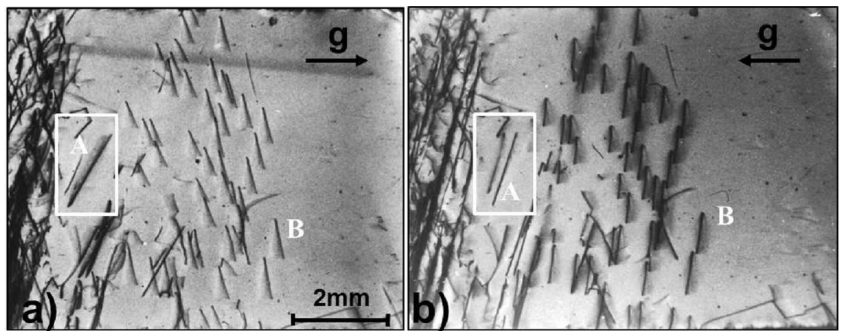

Fig. 4. X-ray transmission projection topographs of the (112)-oriented sample cut out from the $\mathrm{Cz}-\mathrm{Si}$ crystal grown in the $[11 \overline{1}]$ direction, thickness of the sample $d=0.6 \mathrm{~mm}, \operatorname{Mo} K_{\alpha_{1}}$ radiation: (a) $4 \overline{4} 0$, (b) $\overline{4} 40$ reflection. A - the selected $60^{\circ}$ dislocation of the $\frac{1}{2}[1 \overline{1} 0]$ Burgers vector and the $[10 \overline{1}]$ line direction; $\mathrm{B}-$ the selected $90^{\circ}$ dislocations of the $\frac{1}{2}[1 \overline{1} 0]$ Burgers vector and the [110] line direction; $\boldsymbol{g}$ - projection of the diffraction vector on the film. After [5].

tion of the Kato fringes by the diffraction contrast of the dislocation can be also noticed.

Diffraction images of $90^{\circ}$ dislocation (B), observed in section topographs, taken with $\mathrm{Mo} K_{\alpha_{1}}$ and $\mathrm{Cu} K_{\alpha_{1}}$ radiation, are compared in Fig. 6a and 6b. In topographs, taken with highly absorbed $\mathrm{Cu} K_{\alpha_{1}}$ radiation, the interference Kato fringes characteristic for perfect crystal are not visible. The diffraction contrast of the dislocation does not contain the fringes of the "intermediary contrast", too. 


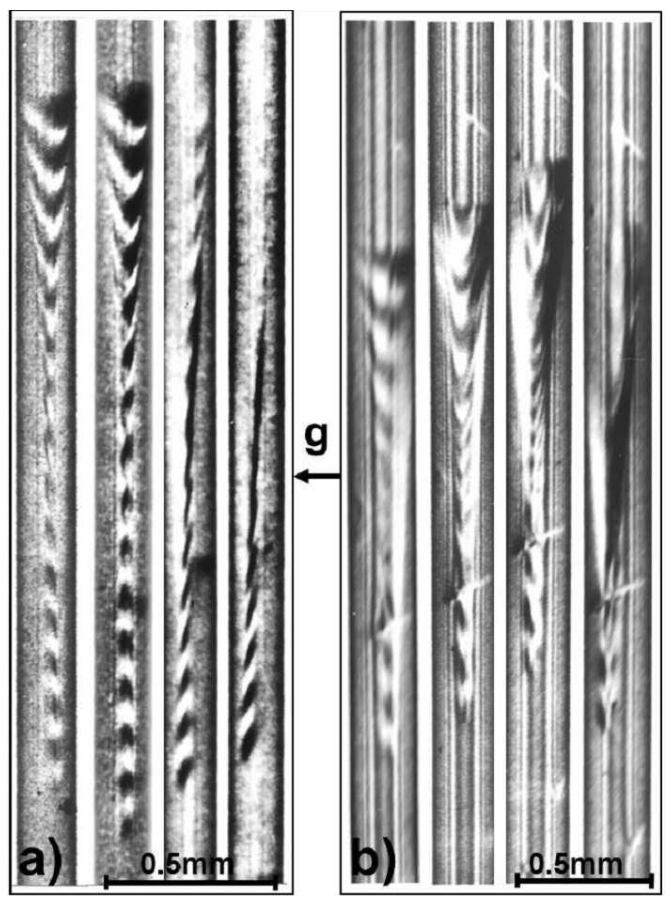

Fig. 5. X-ray section transmission topographs of the region with the selected $60^{\circ}$ dislocation marked by $\mathrm{A}$ in Fig. 4. Topographs taken at successive dislocation positions in the Borrmann triangle; the translation of the crystal with respect to the incident beam were done in steps of $20 \mu \mathrm{m} ; \operatorname{Mo} K_{\alpha_{1}}$ radiation; (a) $1 \overline{1} 1$ reflection; (b) $1 \overline{3} 1$ reflection. $\boldsymbol{g}$ - projection of the diffraction vector on the film. After [5].
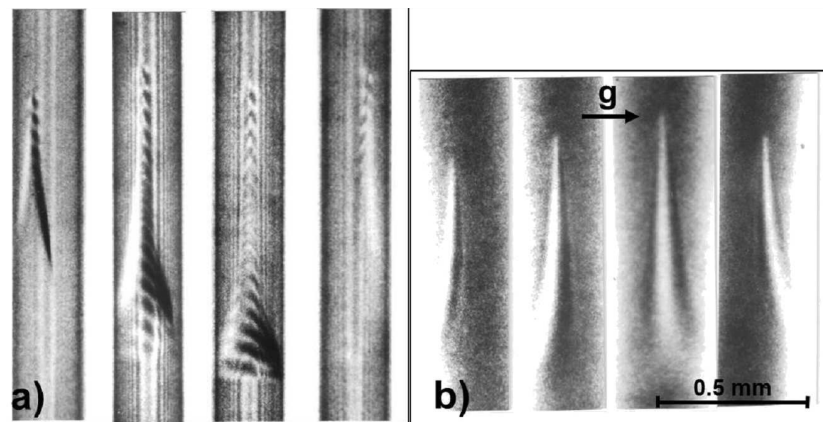

Fig. 6. X-ray section transmission topographs of the region with the selected $90^{\circ}$ dislocation marked by B in Fig. 4, $2 \overline{2} 0$ reflection. Topographs taken at successive dislocation positions in the Borrmann triangle: (a) $\operatorname{Mo} K_{\alpha_{1}}$ radiation $(\mu d=0.94)$; (b) $\mathrm{Cu} K_{\alpha_{1}}$ radiation $(\mu d=8.4)$. The translation of the crystal with respect to the incident beam were done by steps of $30 \mu \mathrm{m}$ (a) and of $50 \mu \mathrm{m}(\mathrm{b})$, respectively. $\boldsymbol{g}$ - projection of the diffraction vector on the film. After [5].

The dislocations set, located in (111) plane, inclined to the (112) crystal surface, allowed for investigation of the dependence of diffraction image on the dislocation distance from the entrance crystal surface [22]. The observed dislocations set, consisting of six dislocations, which line direction changes continuously from direction [hkl] of the first dislocation to $\left[h_{1} k_{1} l_{1}\right]$ of the last one at their end, is shown in Fig. 7a. The formation of the section topograph and position of diffracting plane are schematically shown in Fig. 7b. Section topographs taken for successive positions of dislocations set in relation to the incident beam are shown in Fig. 7c.

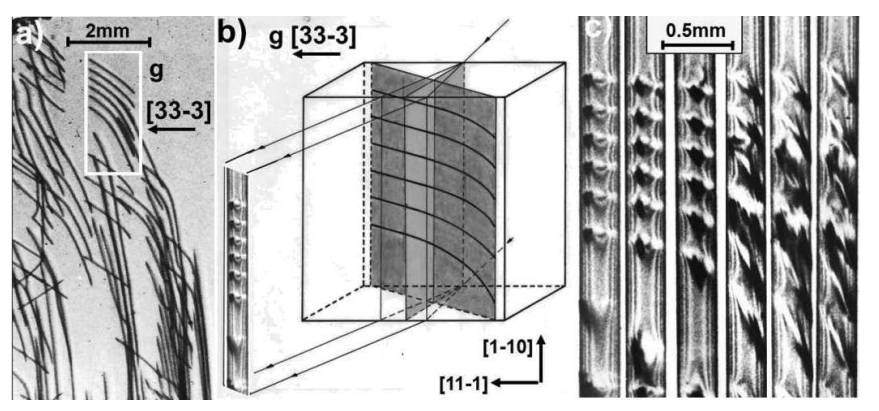

Fig. 7. (a) X-ray transmission projection topograph of (112)-oriented sample cut out from the $\mathrm{Cz}-\mathrm{Si}$ crystal, Mo $K_{\alpha_{1}}$ radiation, $33 \overline{3}$ reflection, thickness of the sample $d=0.4 \mathrm{~mm}$. The dislocations set (the $\frac{1}{2}[01 \overline{1}]$ Burgers vector), located in the (111) plane inclined to the crystal surface, is marked by rectangle border; (b) the schematic formation of the section topograph of the dislocation set, $33 \overline{3}$ reflection; (c) Section topographs taken at successive positions (with translation step of $20 \mu \mathrm{m}$ ) of the dislocations set in respect to the incident beam, $33 \overline{3}$ reflection. $\boldsymbol{g}$ - projection of the diffraction vector on the film. After [20, 22].

\subsubsection{The Czochralski grown $S i_{1-x} G e_{x}$ crystals}

The $\mathrm{Si}_{1-x} \mathrm{Ge}_{x}$ crystals were grown in argon flow atmosphere of $2.0-6.5 \mathrm{kPa}$ pressure with velocity of $4-10 \mathrm{~mm} / \mathrm{h}$, using [111] oriented seed. The investigated samples were cut perpendicularly to the [111] growth axis, mechanically and chemically polished to thickness of $400 \mu \mathrm{m}$. Sample A was cut out from $\mathrm{Si}_{0.988} \mathrm{Ge}_{0.012}$ and sample $\mathrm{B}$ and $\mathrm{C}$ from $\mathrm{Si}_{0.97} \mathrm{Ge}_{0.03}$ of resistivity 0.8 and $3.2-3.7 \Omega$ cm respectively.

Projection transmission topographs, taken for samples A, B and C (Fig. 8a,b,c) show mainly the periodic quasi-circular changes of contrasts, due to non-uniform distribution of Ge atoms in crystal lattice — "striations" [23]. The striations are seen in the sample region surrounding the central "core" region. The contrasts arise as a consequence of lattice parameter changes, related to non-uniform germanium distribution. The observed changes have been confirmed by precise lattice parameter measurement with the Bond method.

The section topographs, reveal the contrasts, due to "striations", too (Fig. 8e,f). In topographs, taken for crystal B in two places (arrows in Fig. 8b), one can recognize lines of black and white contrasts, corresponding to the quasi-circles seen in projection topographs. Their inclination to the vertical edge of the section topograph correspond to the direction of the line in the projection topograph. 


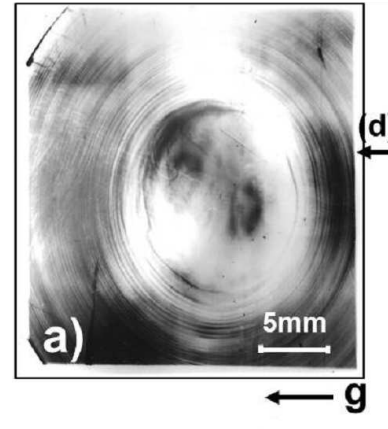

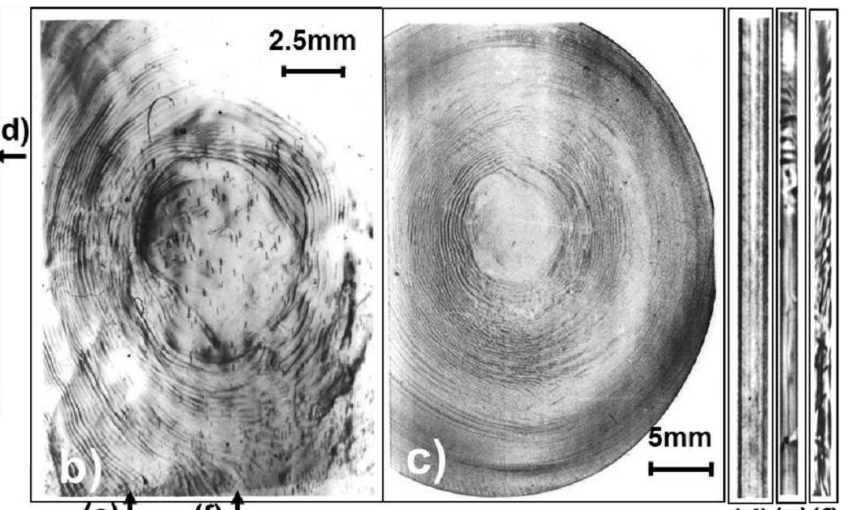

(f) $\uparrow$ (d)(e)(f)

Fig. 8. X-ray diffraction transmission topographs of the $\mathrm{Si}_{1-x} \mathrm{Ge}_{x}$ crystals grown in the [111] direction, $22 \overline{4}$ reflection: (a,d) $x=0.012 ;(\mathrm{b}, \mathrm{c}, \mathrm{e}, \mathrm{f}) x=0.03$. (a-c) projection topographs; (d-f) section topographs taken along the direction denoted by arrows in (a) and (b); (a, b), (d-f) $\mathrm{MoK} K_{\alpha_{1}}$ radiation, (c) $\operatorname{Ag} K_{\alpha_{1}}$ radiation. $\boldsymbol{g}$ - projection of the diffraction vector on the film. After [23].

The interference structure (Kato fringes) in topographs of crystal B are not seen even in its "core" region. The section topograph of crystal A (Fig. 8d) was taken in crystal position marked by arrow in Fig. 8a. The distinct Kato fringes are seen.

The "core" parts, however, do not exhibit ideal crystal lattice. The contrasts, related to strains in sample A, and dislocations in sample B, are seen. Moreover, for sample A, the core structure is observed to be nonuniform - this nonuniformity can be related to smaller micro-defects, non-detected in topographs due to the small size of the strain field induced by a single defect (the size being below the detection limit of the method) - this was confirmed by the section-topograph simulation [23].

\subsubsection{The Czochralski grown oxide materials}

The Czochralski technique is also a suitable method for growth and production of bulk oxide crystals, which are important materials for applications as elements of electronic and optical devices and suitable substrate for deposition on various thin films. The crystals may contain various growth defects such as growth striations, dislocations, inclusions, precipitations or block structures. All these defects could limit considerably possible applications of the crystals. Thus, understanding of mechanisms of crystal lattice defects formation is very important for technology [24].

We present some results of X-ray Lang topographic investigations of selected oxide materials of a tetragonal structure to show variety of observed growth defects in these crystals. It is worth noting that the occurrence of a particular defect structure depends not only on chemical composition, kinds of dopants and level of doping, but also on the growth conditions, such as the crystallization direction, an atmosphere in a growth chamber and a stage of crystallization process [24,25]. The studies show that X-ray topographic methods - very sensitive to the crystal lattice deformation - are suitable technique to reveal and identification of crystal lattice defects also in these materials.
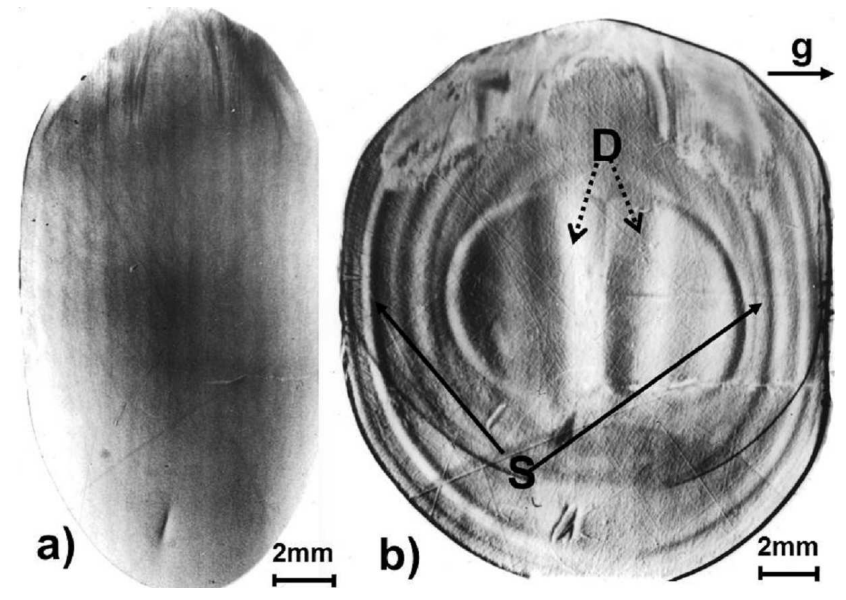

Fig. 9. X-ray projection topographs of the (100)-oriented $\mathrm{SrLaGaO}_{4}$ crystal, $\mathrm{Mo} K_{\alpha_{1}}$ radiation: (a) back-reflection topograph, 501 reflection; (b) transmission topograph, 006 reflection. $g$ - projection of the diffraction vector on the film. D - the characteristic "double" core. S - examples of the striation rings.

The first group are materials of general composition $\mathrm{ABCO}_{4}$ (where $\mathrm{A}=\mathrm{Ca}, \mathrm{Sr}$ or $\mathrm{Ba} ; \mathrm{B}=\mathrm{La}, \mathrm{Nd}$ or Pr; $\mathrm{C}=\mathrm{Al}$ or $\mathrm{Ga}$ ) with the tetragonal perovskite-related $\mathrm{K}_{2} \mathrm{NiF}_{4}$-type structure (space group $I 4 / \mathrm{mmm}$ ). Owing to their electrochemical, dielectric and thermal properties and good lattice matching, $\mathrm{ABCO}_{4}$ crystals are applicable materials used as substrate materials for high temperature superconductor thin films, elements of thermal radiation receivers and other electronic and optical devices [25 and references therein]. $\mathrm{SrLaGaO}_{4}$ (SLG) crystal is the most promising material from this group [25].

The Czochralski growth of the SLG crystals is strongly dependent, among others conditions, on direction of crystallisation and an oxygen content in a nitrogen atmosphere in growth chamber. The crystals are relatively 
easily grow in [100] direction [25]. For such crystals, neither inclusions nor dislocations were observed by X-ray topography. Only growth striations and a double core were revealed (Fig. 9), probably connected with the growth on (101) and (10̄) facets [26].

The growth in [001] direction with the flat (001) inter- face - more attractive for the possible application — was more difficult and was only possible at an oxygen content in nitrogen atmosphere not lower than $4 \times 10^{-3}$ at. $\%$. The obtained crystals were characterized by a high defect density. The defects observed for such crystals have been attributed to local growth surface instabilities [25].

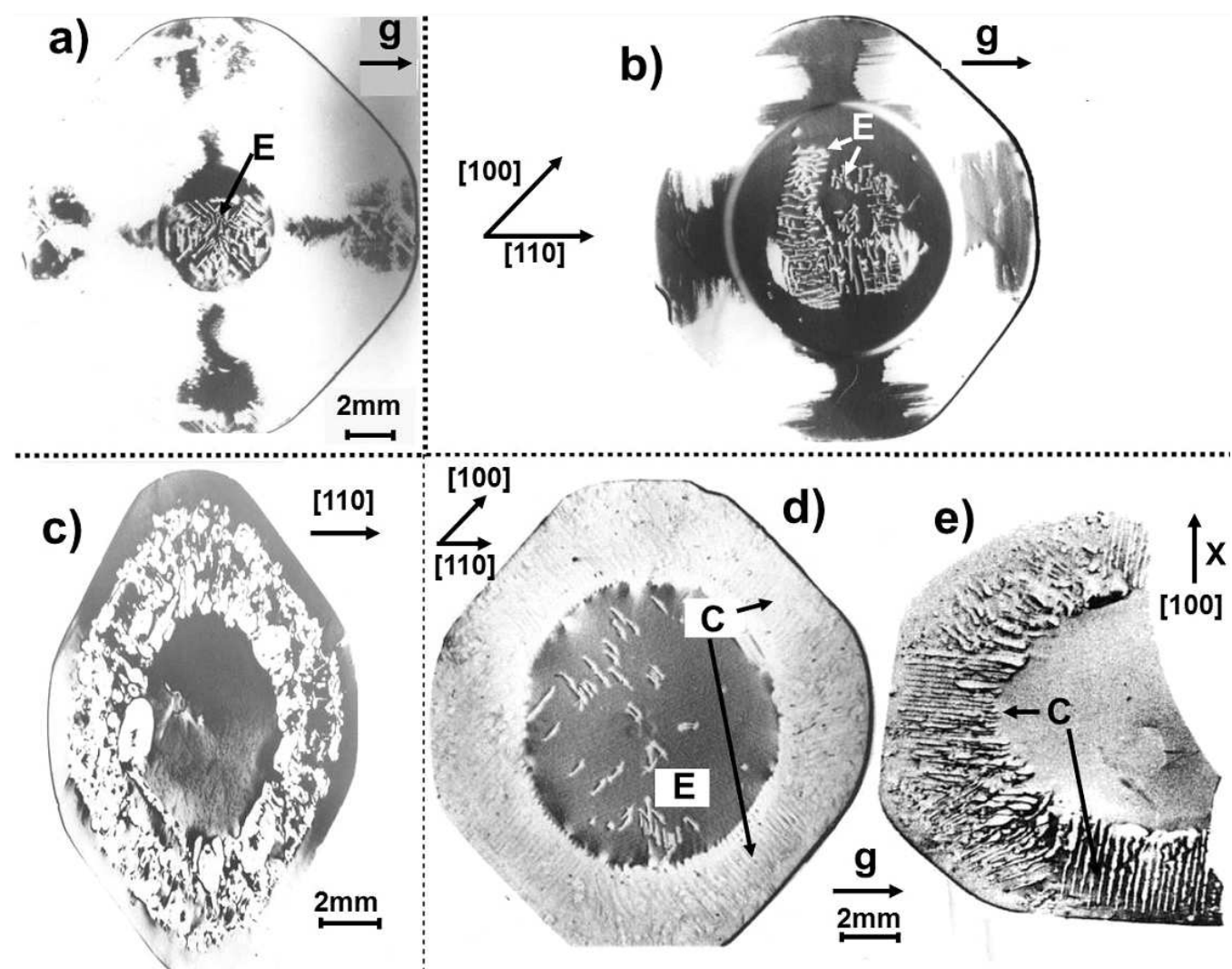

Fig. 10. X-ray projection topographs of (001)-oriented $\mathrm{SrLaGaO}_{4}$ crystals, obtained using the Mo $K_{\alpha_{1}}$ radiation. (a-b) samples cut out from the crystal grown in the $\mathrm{N}_{2}$ atmosphere with the $1.7 \times 10^{3}$ ppm oxygen content: (a) near seed part, $d=501 \mu \mathrm{m}, 110$ reflection; (b) near end part, $d=505 \mu \mathrm{m}, 110$ reflection; (c-e) samples cut out from the crystals grown in the $\mathrm{N}_{2}$ atmosphere with $7.5 \times 10^{3} \mathrm{ppm} \mathrm{O}_{2}$ : (c) near seed part, $d=520 \mu \mathrm{m}$, back-reflection topograph, 1114 reflection; (d) near end part, $d=255 \mu \mathrm{m}$, transmission topograph, 220 reflection; (e) near end part, $d=490 \mu \mathrm{m}$, back-reflection topograph, 107 reflection. $\boldsymbol{g}$ denotes projection of the diffraction vector on the film; X denotes projection of the incident beam direction on the film; E, C - examples of the diffraction contrast corresponding to the "rod-like" defects and the cellular structure, respectively. After [27-30].

Figure 10 presents topographs of (001)-oriented samples cut out from crystals grown in nitrogen atmosphere with two various oxygen contents: $1.7 \times 10^{3} \mathrm{ppm}$ or $7.5 \times 10^{3} \mathrm{ppm}$. For each crystal two samples (one cut near the seed and the other - near the end) represented two various stages of growth process were investigated. One can notice following characteristic features of the revealed defect structure [27-33]:

- The central core region, which is more perfect, is very well separated from the outer part of the sample.

- The tendency of enlarging of the core region in the end part of the crystal is observed.
- For the crystals grown in $\mathrm{N}_{2}$ atmosphere with $1.7 \times 10^{3} \mathrm{ppm} \mathrm{O}_{2}$ : the linear diffraction contrasts (probably associated with dislocations) with the different density in various places of the outer region are observed. The long-range strains corresponding to the outer region structure cause the differences in the diffracted beam intensity, which is well visible in Fig. 10a,b [28].

- For the crystals grown in $\mathrm{N}_{2}$ atmosphere with $7.5 \times 10^{3} \mathrm{ppm} \mathrm{O}_{2}$ : the diffraction contrast of irregular shapes related to volume defects (near the seed part of the crystal, Fig. 10c) and linear black and white diffraction contrast arranged in the $\langle 100\rangle$ 
or $\langle 010\rangle$ directions (the end part of the crystal) (marked by $\mathrm{C}$ in Fig. 10d,e) are observed in the outer region [27-29]. They are related to the faceted growth which probably occurs at the end of the growth process and results in cellular structure of the crystal; the beginning of interface fluctuations and cellular growth seems to take place at the core edge, where growth on (001) plane switches to growth on $\{103\}$ planes $[25,28]$. The optical transmission microscopy investigations reveal also some dendritic forms, which often coexist with the cellular structure.

- Characteristic network of linear diffraction contrasts, arranged in rows along the $\langle 100\rangle$ and $\langle 110\rangle$ directions, was detected in the core region of the all samples (marked by E in Fig. 10); the kind of regularity of these contrasts is notably well seen in the samples cut out from the end parts of the crystals (Fig. 10b,d). The X-ray topographic and optical microscopic investigations revealed that the contrasts correspond to the rows of rod-like defects, which extend deeply into the samples, inclined to the (001) sample surface and form a kind of walls aligned in the $\{100\}$ or $\{110\}$ lattice planes, [28-33]. The "rod-like" defects are built probably from the same phase crystallizing at a moment different from the rest of the crystal. Diffraction contrasts have been studied in detail at different diffraction conditions by means of various topographic techniques [28-34], permitting to determine the character of crystal lattice deformation around the defects in SLG. It has been shown that the lattice bending is caused by the shrinkage of the material inside the rod-like volume defects along their lengths [29-34].

The crystals of solid solution in the systems $\mathrm{A}_{x} \mathrm{~A}^{\prime}{ }_{1-x} \mathrm{BCO}_{4}$ or $\mathrm{ABC}_{x} \mathrm{C}^{\prime}{ }_{1-x} \mathrm{O}_{4}$ give the possibility of obtaining the required lattice parameter by the selection of the $\mathrm{A} / \mathrm{A}^{\prime}$ or $\mathrm{C} / \mathrm{C}^{\prime}$ ratios $[25,35]$ (the selection is of importance from the point of view of minimizing the lattice mismatch between the substrate single crystal and single crystalline layer or multilayer). The topographs of the selected [100]-oriented $\mathrm{Ca}_{x} \mathrm{Sr}_{1-x} \mathrm{NdAlO}_{4}$ single crystals (solid solutions of $\mathrm{SrNdAlO}_{4}-\mathrm{CaNdAlO}_{4}$ ) with $x=0.25$; 0.5 and 0.75 are presented in Fig. 11.

The main defects revealed in $\mathrm{Ca}_{0.25} \mathrm{Sr}_{0.75} \mathrm{NdAlO}_{4}$ and $\mathrm{Ca}_{0.5} \mathrm{Sr}_{0.5} \mathrm{NdAlO}_{4}$ samples, cut out perpendicularly to the [100] growth axis, are the striation fringes associated with non-homogenous crystal chemical composition, which is typical for both, solid solutions and doped crystals. They are observed as diffraction contrasts of distinct fringes in the form of concentric rings of relatively large periods accompanied by much weaker dense fringes between them (Fig. 11a,b). Density of the fringes are different in both crystals. Detailed studies of the lattice deformation associated with the segregation fringes were performed by means of synchrotron topography and is presented in $[33,36]$.

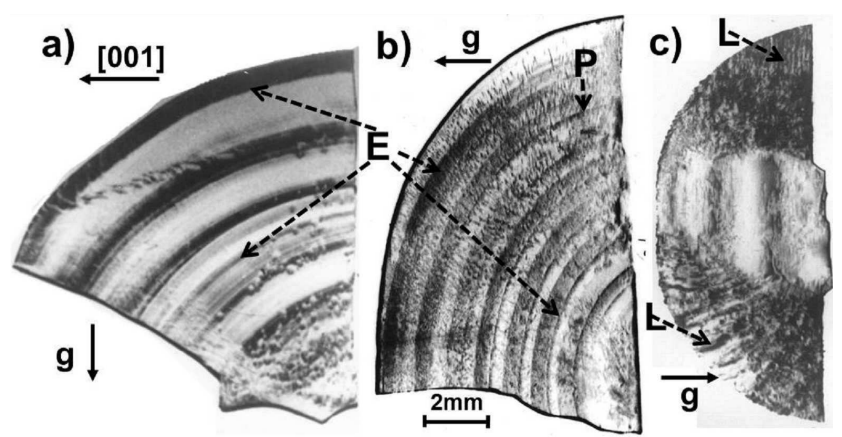

Fig. 11. X-ray projection transmission topographs of the samples cut out from the selected (100)-oriented $\mathrm{Ca}_{x} \mathrm{Sr}_{1-x} \mathrm{NdAlO}_{4}$ single crystals, MoK $K_{\alpha_{1}}$ radiation: (a) $\mathrm{Ca}_{0.25} \mathrm{Sr}_{0.75} \mathrm{NdAlO}_{4}$ single crystal, $02 \overline{0}$ reflection; (b) $\mathrm{Ca}_{0.5} \mathrm{Sr}_{0.5} \mathrm{NdAlO}_{4}$ single crystal, 008 reflection; (c) $\mathrm{Ca}_{0.75} \mathrm{Sr}_{0.25} \mathrm{NdAlO}_{4}$ single crystal, $00 \overline{4}$ reflection. $\boldsymbol{g}$ denotes the projection of the diffraction vector on the film. $E$ - examples of the diffraction contrast corresponding to the rings of the striations; $P$ - the example of the ring of the striation, probably decorated by small precipitates; $L$ - linear black contrasts arrange along the lines of intersections of the (010) and (011) lattice planes with the sample surface. After [36, 37].

Apart from striations, the topographs revealed a significant concentration of individual defects. Some of the observed contrasts were attributed to volume defects, most probably representing "rod-like" inclusions, similar to those found in the core of SLG crystals. This was confirmed by synchrotron topography investigations and numerical simulation of the synchrotron topographic images [32-34]. For $\mathrm{Ca}_{0.5} \mathrm{Sr}_{0.5} \mathrm{NdAlO}_{4}$ sample, contrasts of a different type are found. They are mostly similar to dislocation contrasts.

The defect structure of $\mathrm{Ca}_{0.75} \mathrm{Sr}_{0.25} \mathrm{NdAlO}_{4}$ crystal is markedly different from that of $\mathrm{Ca}_{0.25} \mathrm{Sr}_{0.75} \mathrm{NdAlO}_{4}$ and $\mathrm{Ca}_{0.5} \mathrm{Sr}_{0.5} \mathrm{NdAlO}_{4}$ single crystals (Fig. 11c). No segregation fringes in the form of concentric rings are observed. A more perfect central region is visible. In other parts of the image, linear black contrasts are arranged along the lines of intersections of the $\{010\}$ and $\{011\}$ lattice planes with the sample surface (the examples marked by $\mathrm{L}$ in Fig. 11c). A relatively high density of point-like black contrasts associated probably with precipitates (inclusions) are revealed, especially in the regions with linear contrasts.

Zircon-type rare earth orthovanadates $\mathrm{REVO}_{4}$ (space group $I 4_{1} /$ amd ), promising optical materials for applications in lasers and polarisers, are the second group of investigated oxide materials. Difficulties associated with growing of good quality $\mathrm{REVO}_{4}$ crystals are connected mainly with low thermal conductivity of these materials. The low conductivity is supposed to result in occurrence of the block structure. Studies of samples cut out from various regions of the undoped and doped $\mathrm{YVO}_{4}$ and $\mathrm{GdVO}_{4}$ single crystals enabled to reveal some changes of defect structure during the growth process and changes caused by specific doping [38-40]. 
The Lang projections topographs of $\mathrm{YVO}_{4}$ and $\mathrm{GdVO}_{4}$ single crystals reveal several regions with different blackening corresponding to the blocks with different inclina- tion to the sample surface and set not exactly in reflecting position (marked by B in Figs. 12 and 13).

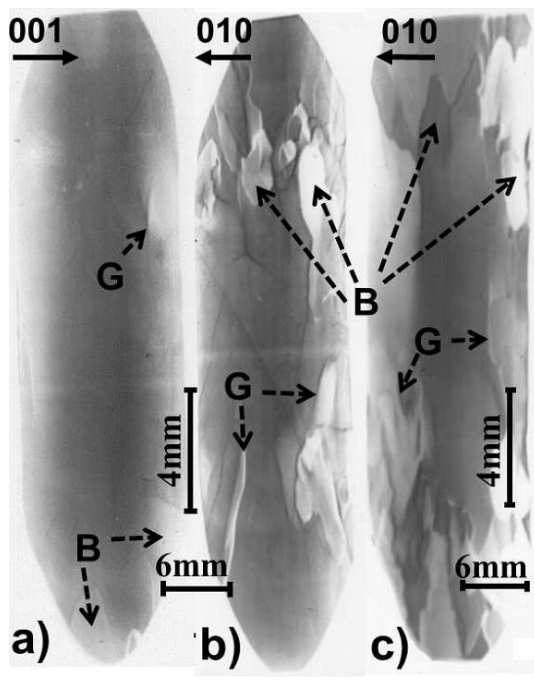

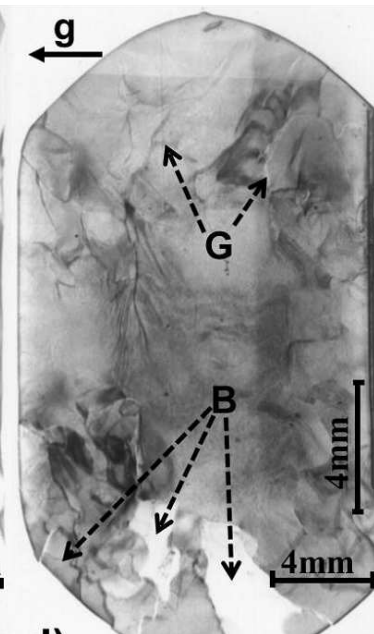

d)
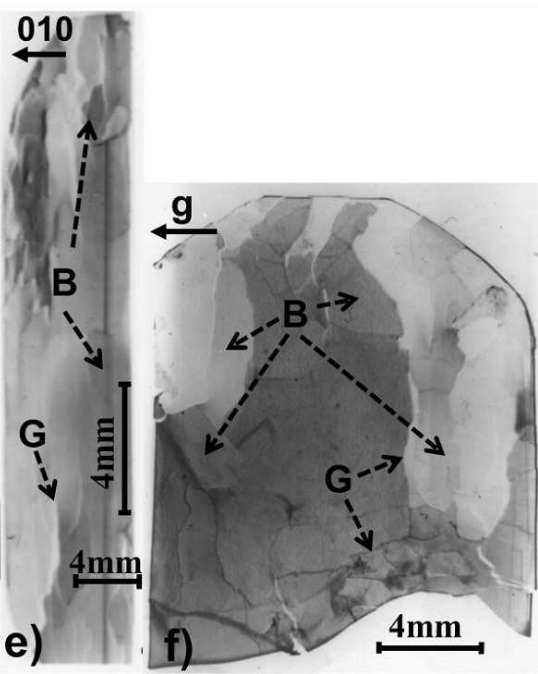

Fig. 12. X-ray projection topographs of the $\mathrm{YVO}_{4}$ single crystals, MoK $K_{\alpha_{1}}$ radiation: (a) undoped crystal; (b-e) Er doped crystal $(0.5$ at.\% Er); (f) Ca doped crystal $(0.4$ at.\% Ca). (b,f) samples cut out near the seed part of the crystal; (a, c, d) samples cut out near the middle part; (e) sample cut out near the end part; (a-c,e) back-reflection topographs, 800 reflection; (d,f) transmission topographs, 020 reflection. $\boldsymbol{g}$ - projection of the diffraction vector on the film; B - examples of crystal blocks, G - examples of grain boundaries. After [38, 39].
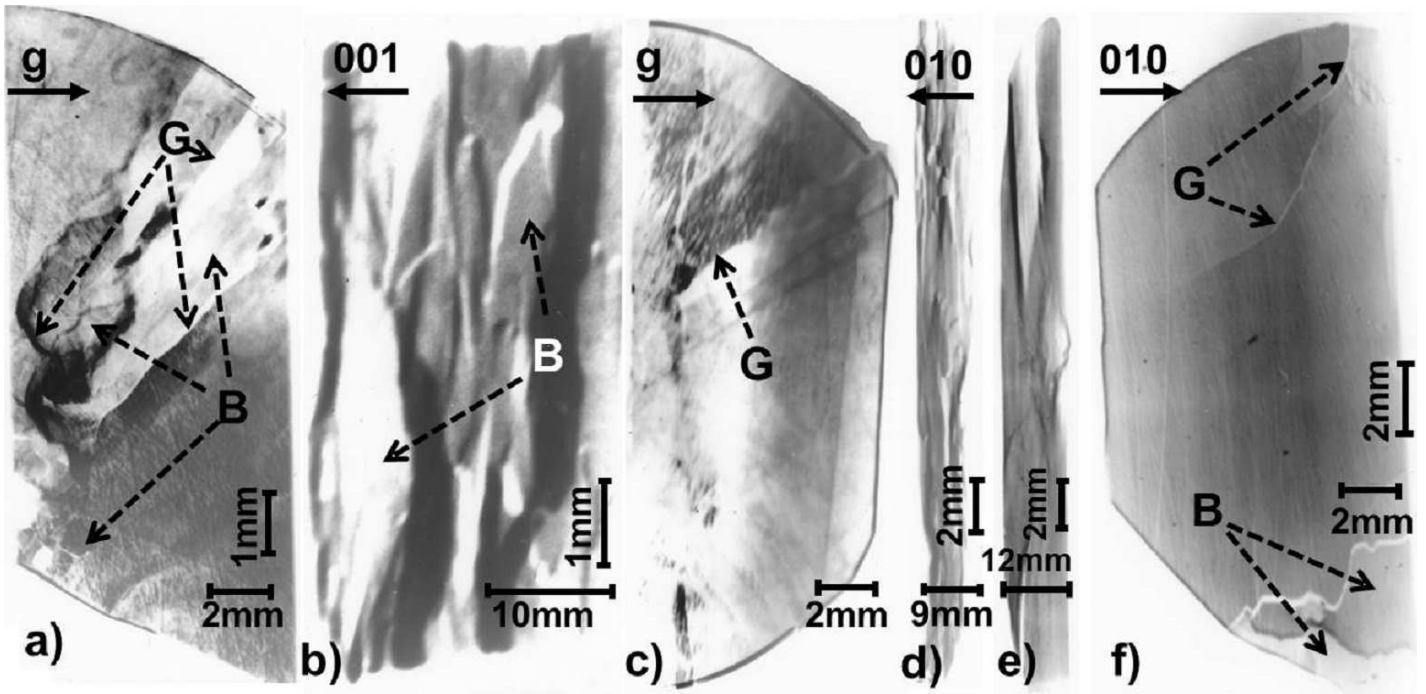

Fig. 13. X-ray projection topographs of the samples cut out from the near seed part (a,c,e) and from the near end part (b, d,f) of the $\mathrm{GdVO}_{4}$ crystals, MoK $\alpha_{1}$ radiation: (a,b) undoped crystal; (c, d) Er doped crystal $(0.5$ at.\% Er); (e,f) Tm doped crystal (4 at.\% Tm). (a,c) transmission topographs, 020 reflection; (b, d, e) back-reflection topographs, 400 reflection; (f) asymmetric back-reflection topograph, $10 \overline{4} 0$ reflection. $\boldsymbol{g}$ - projection of the diffraction vector on the film. After [40].

For $\mathrm{YVO}_{4}$, no significant differences between the samples cut out from various regions of the crystals were observed (Fig. 12) [38, 39]. It was indicated, however, that in the $\mathrm{GdVO}_{4}$ the block structure is much more developed in samples cut out from the end part of the crystal than that from the near seed part (Fig. 13a-d).
The $\mathrm{GdVO}_{4}$ containing thulium at a relatively high concentration level (4\%) is an exception - the mosaic structure is practically absent in the end part (Fig. 13e,f) [40]. The topographs of this crystal revealed the highest quality among all studied $\mathrm{REVO}_{4}$ materials. The most developed mosaic block structure seems to be observed in 
both $\mathrm{YVO}_{4}$ and $\mathrm{GdVO}_{4}$ crystals doped with 0.5 at.\% Er and $\mathrm{YVO}_{4}$ : $\mathrm{Ca}(0.4$ at.\%) (Figs. 12, 13). These results were supported by synchrotron topographic investigation, which additionally enabled detailed analysis of crystal lattice deformation near block boundaries and permitted to evaluate of mean block misorientation [33, 38-40].

For several oxide crystals analyzed in the present study, complementary investigations using X-ray topography employing a synchrotron source have been performed in parallel and are presented by Wierzchowski et al. [33].

\section{Topography for thermally processed crystals}

The dislocation free $\mathrm{Cz}-\mathrm{Si}$ contains the point defects such as intentionally added dopant atoms or impurity atoms (mainly interstitial oxygen atoms) non-intentionally induced during growth. In the course of the post growth technological process, performed at high temperature, a new defects can be generated. During the annealing process the oxygen atoms agglomerate and form silicon oxide precipitates and oxygen-related micro-defects. The form and dimension of precipitates and kind of micro-defects and their density depend on the impurities content, the temperature and time of the annealing process and on the thermal crystal history as well [41].

\section{1. $C z-S i$ subjected to thermal oxidation}

The Czochralski grown dislocation-free silicon crystals subjected to thermal oxidation was studied in [42]. Investigated samples were cut out perpendicularly to the [111] growth axis from the $p$-type boron doped Si. Samples were mechanically and chemically polished to the $300 \mu \mathrm{m}$ thickness. The $\mathrm{SiO}_{2}$ layer about $5000 \AA$ thick
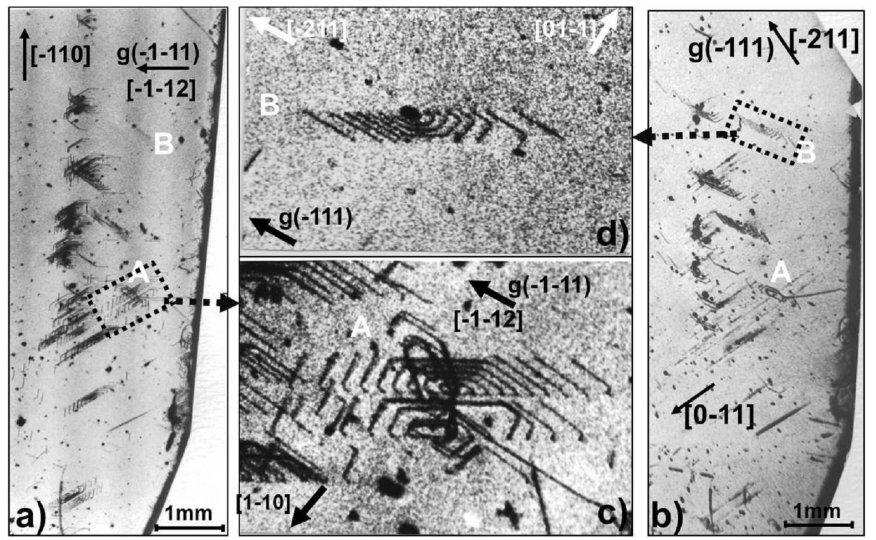

Fig. 14. X-ray transmission projection topographs of $\mathrm{Cz}-\mathrm{Si}$ crystal grown in the [111] direction, sample cut out perpendicularly to the growth axis, $d=0.3 \mathrm{~mm}$, $M o K_{\alpha_{1}}$ radiation. The samples were subjected to thermal oxidation at $1180^{\circ} \mathrm{C}$ in a wet oxygen atmosphere forming an $\approx 5000 \AA$ thick $\mathrm{SiO}_{2}$ layer. (a, c) $\overline{1} 11$ reflection, (b, d) $\overline{1} 11$ reflection; (c, d) enlarged topographs of the loops A and B respectively. $\boldsymbol{g}$ - projection of the diffraction vector on the film. After [42] was formed during thermal oxidation process at $1180^{\circ} \mathrm{C}$ in a wet oxygen atmosphere. Projection transmission Lang topographs were taken for several $h k l$ reflections using $\operatorname{Mo} K_{\alpha_{1}}$ radiation, and recorded on Ilford G5 nuclear emulsions, $50 \mu \mathrm{m}$ thick.

Dislocation loops - located in (111) and (1111) planes - generated at precipitates, were observed. The loops A and B (Fig. 14) were analyzed owing to their well developed segments and good separation from other spirals. The Burgers vectors of the defects have been determined using the kinematical invisibility criteria. The loop A of the $\frac{1}{2}[1 \overline{1} 0]$ Burgers vector consists of two sets of $60^{\circ}$ dislocations and a set of screw ones, parallel to the crystal surface. During growth of the loop, the screw segments reaching the surface disappear, whereas the $60^{\circ}$ ones propagate in the crystal forming the rows of parallel dislocations. Similarly, the spiral B of the $\frac{1}{2}[011]$ Burgers vector, lying in the (111) plane is formed of $60^{\circ}$ and screw, parallel to the surface, dislocations.

\subsection{Cz-Si subjected to high temperature (HT) and high pressure (HP) treatment}

The systematic studies of defects generated by simultaneous applying the high temperature and high pressure annealing in dislocation free $\mathrm{Cz}-\mathrm{Si}$, were performed in $[43,44]$. The as grown crystals — with various oxygen

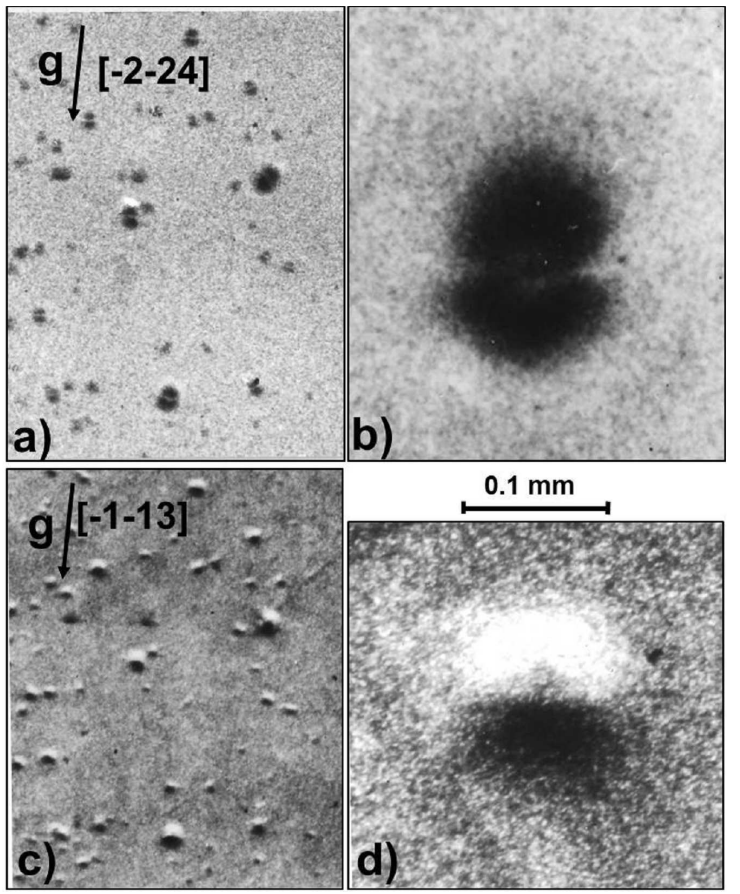

Fig. 15. X-ray transmission projection topographs of the $\mathrm{Cz}-\mathrm{Si}$ crystal grown in the [111] direction. The sample (cut out perpendicularly to the growth axis and previously defects free), after annealing at $700{ }^{\circ} \mathrm{C}$ and $7 \mathrm{kbar}(\mathrm{Ar})$ for $1 \mathrm{~h}$ : (a, b) $\overline{2} \overline{2} 4$ reflection, $\operatorname{Mo} K_{\alpha_{1}}$ radiation $(\mathrm{c}, \mathrm{d}) \overline{1} \overline{1} 3$ reflection, $\mathrm{Cu} K_{\alpha_{1}}$ radiation $(\mathrm{b}, \mathrm{d})$ enlarged diffraction contrasts of the selected spherical stress centers from the topographs (a) and (c), respectively. After [43, 44]. 
content, and phosphorus or boron doped - were investigated, applying temperatures in range of $300-1200^{\circ} \mathrm{C}$, and pressures from $3 \mathrm{MPa}$ to $1.2 \mathrm{GPa}$ (30 bar to $12 \mathrm{kbar}$ ) in the argon or helium atmosphere. The studies, performed by X-ray diffraction projection transmission topography, allowed to detect and characterize the generated defects as precipitates and dislocations.

The $\mathrm{Cz}_{\mathrm{z}} \mathrm{Si}$ crystals, after high temperature-high pressure treatment contained quasi-spherical defects (Fig. 15), giving characteristic two-lobe contrast (divided by "line of no contrast") having its source in the stress related to the second-phase precipitates $[45,46]$. The line of no contrast is perpendicular to the diffraction vector $\boldsymbol{g}$ for spherical inclusions, but in the case of non-spherical precipitates, this condition is not fulfilled. The contrast, observed in the topograph taken with $\operatorname{Mo} K_{\alpha_{1}}$ radiation for a sample of $300 \mu \mathrm{m}$ thick $(\mu d=0.4)$, is black (Fig. 15a,b); in topograph, obtained with $\mathrm{Cu} K_{\alpha_{1}}$ radiation $(\mu d=10)$ the contrast consists of one black and one white lobe (Fig. 15c,d). The sign of the stress (corresponding to the compressive or tensile state) can be deduced from sequence of the white-black contrast in respect to the direction of diffraction vector $\boldsymbol{g}[45,46]$.

In the crystals, subjected to high pressure and the highest temperatures employed $\left(1000-1200^{\circ} \mathrm{C}\right)$, other defects - dislocations, besides the precipitates - were observed.
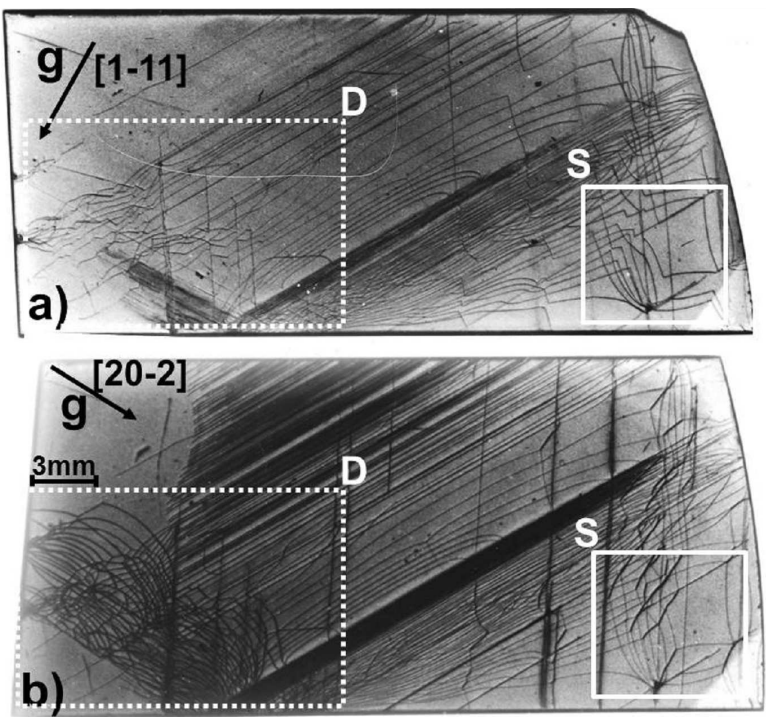

Fig. 16. X-ray transmission projection topographs of the $\mathrm{Cz}-\mathrm{Si}$ crystal grown in the [111] direction. The sample (cut out perpendicularly to the growth axis) after annealing at 4 kbar and $1075^{\circ} \mathrm{C}$ during $1 \mathrm{~h}$ in $\mathrm{Ar}$; Mo $K_{\alpha_{1}}$ radiation: (a) $1 \overline{1} 1$ reflection; (b) $20 \overline{2}$ reflection. $\mathrm{D}, \mathrm{S}-$ selected groups of dislocations; different parts of dislocation sets are visible in both topographs; $\boldsymbol{g}$ projection of the diffraction vector on the film. After $[43,44]$.

Some of them were generated at the sample surface; one set of dislocations was formed at the internal source of shear stress (marked by S in Fig. 16). Different dis-

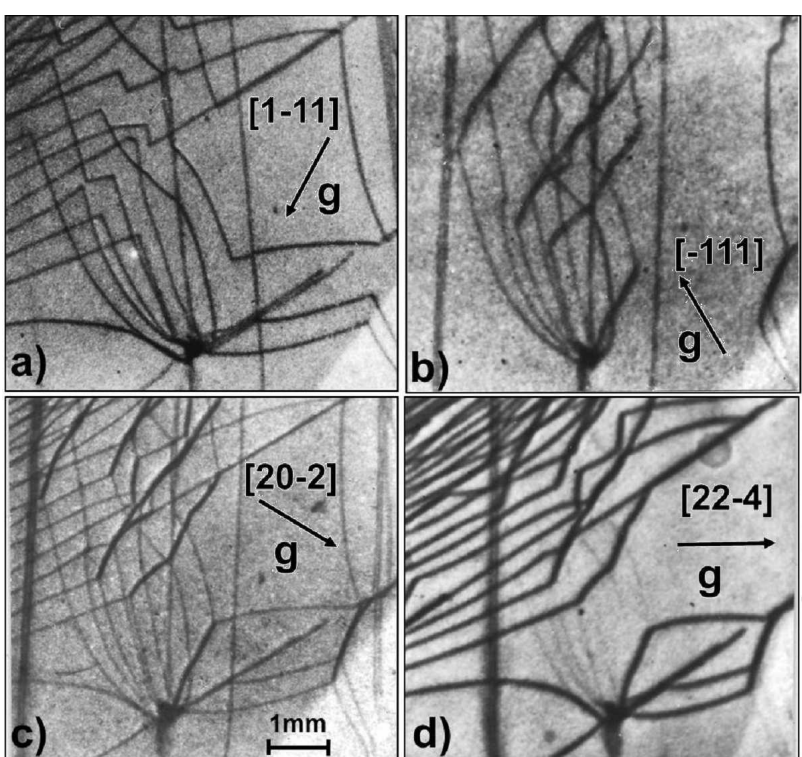

Fig. 17. X-ray transmission projection topographs showing dislocations sets (located in the region $\mathrm{S}$ marked in Fig. 16) generated at spherical stress centers; $\operatorname{MoK} \alpha_{1}$ radiation, reflections: (a) $1 \overline{1} 1$, (b) $\overline{1} 11$, (c) $20 \overline{2}$, (d) $22 \overline{4}$; different parts of dislocation sets are visible in topographs taken in different reflections. $g$ projection of the diffraction vector on the film. After $[43,44]$.

locations in the set have various Burgers vectors, and in the topograph taken with a given diffraction vector $\boldsymbol{g}_{h k l}$ only one part of set is seen with high contrast (Fig. 17).

\section{3. $C z-S i$ subjected to high temperature two-step annealing}

The process of oxygen precipitation and formation of oxygen-related micro defects being formed during annealing of $\mathrm{Cz}-\mathrm{Si}$ crystals have been investigated with various methods (for a review, see [41]).

The X-ray diffraction topographic studies of $\mathrm{Cz}_{-}-\mathrm{Si}$ crystals of high oxygen content, subjected to two-step annealing, were performed in [47-50]. The three samples (A, B and $\mathrm{C}$ ) were annealed at $1423 \mathrm{~K}$ during 4, 8 or $10 \mathrm{~h}$, respectively. Before treatment at $1423 \mathrm{~K}$ all samples were preannealed at $1173 \mathrm{~K}$ during $75 \mathrm{~min}$. This annealing step is especially important, because the nucleation process of silicon oxide precipitates takes place at lower temperature. The subsequent annealing at a higher temperature causes further development of the precipitates and formation of secondary oxygen-related micro defects [41]. In the last annealing step the samples were cooled back to $1173 \mathrm{~K}$ in $1 \mathrm{~h}$.

The characteristic "spot-like" contrasts with various density and dimensions were observed in projection topographs of all samples (Fig. 18a-d). Most of contrasts are of the irregular shape, but in the topograph of sample B one can distinguish the contrasts with six fold symmetry - either fully black or a black contour surround- 


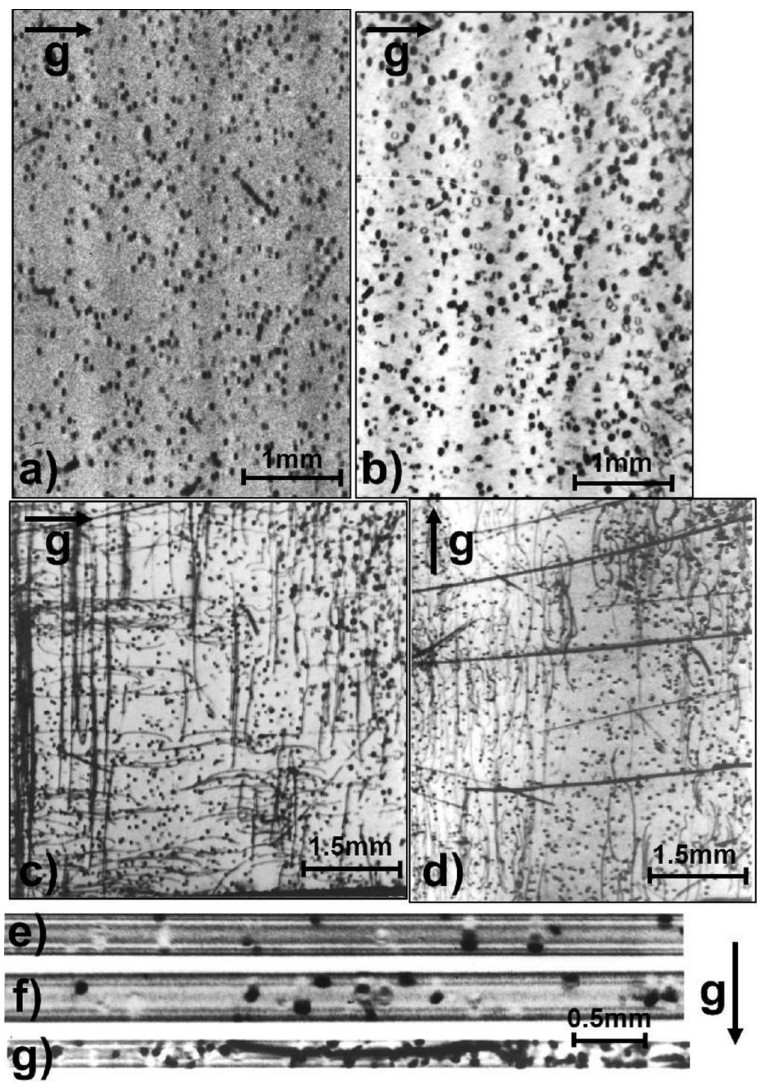

Fig. 18. X-ray transmission topographs of the $\mathrm{Cz}-\mathrm{Si}$ crystals grown in the [001] direction; (001)-oriented samples after annealing in two step process: first step at $1173 \mathrm{~K}$ during $1.5 \mathrm{~h}$ and second step - at $1423 \mathrm{~K}$ for $4 \mathrm{~h}(\mathrm{a}, \mathrm{e}), 8 \mathrm{~h}(\mathrm{~b}, \mathrm{f})$ and $10 \mathrm{~h}(\mathrm{c}, \mathrm{d}, \mathrm{g})$; MoK $K_{\alpha_{1}}$ radiation; (a-d) projection topographs, reflections: (a) $\overline{2} 20$, (b) 220 , (c) $\overline{2} 20$ (d) 220 . (e-g) section topographs taken with reflections: (e) $\overline{4} 40$, (f) 440, (g) $4 \overline{4} 0$. After [47-50].

ing the white part inside (Fig. 18b). The most frequent are two-lobe contrasts, the source of which is the lattice deformation around the precipitates of the silicon oxide phase. For spherical precipitates the no-contrast line is perpendicular to the diffraction vector $\boldsymbol{g}$. The density of "spot-like" contrasts decreases with increasing of annealing time, whereas the mean contrast diameter increases. The shapes of "spot-like" contrasts, related to precipitates, are clearly seen in section topographs of samples A, B and C (Fig. 18e,f,g).

In the sample $\mathrm{C}$, annealed at $1423 \mathrm{~K}$ during $10 \mathrm{~h}$, long curved dislocations were observed (Fig. $18 \mathrm{c}, \mathrm{d}$ ). Some of them seem to be anchored at their "ends" to precipitates - they probably outcrop to the surface close to the precipitate. Such dislocations were well seen in the section topograph (Fig. 18g).

\section{Summary}

The conventional X-ray diffraction topography is a method suitable for revealing and characterization of crystal lattice defects, due to its sensitivity to the deformation of lattice planes. In the present study, the topographic images of the defects in selected crystals grown by the Czochralski method were presented. The defect structure of a crystal depends on the chemical composition, growth conditions and on details of post growth thermal annealing process. The presented results include:

- the growth dislocations in some of the early silicon crystals,

- the striations related to the some segregation effects in $\mathrm{Si}_{1-x} \mathrm{Ge}_{x}$ and solid solutions $\mathrm{Ca}_{x} \mathrm{Sr}_{1-x} \mathrm{NdAlO}_{4}$,

- defects generated in silicon crystals during the post growth technological processes,

- cellular structure in the outer shell and the characteristic rod-like defects arranged in networks in the core of $\mathrm{SrLaGaO}_{4}$ crystals grown in [001] direction,

- variously developed block structure in selected $\mathrm{REVO}_{4}$ crystals.

\section{Acknowledgments}

The results were obtained thanks to the long-time cooperation of Colleagues from the X-ray Laboratory at the Institute of Experimental Physics in University of Warsaw and from the Institute of Electronic Materials Technology (Warsaw), where all investigated crystals were grown. The Authors are very grateful to all Colleagues and Coworkers for their contributions to the work.

Special thanks go to Professor A. Pajaczkowska, Professor T. Łukasiewicz, B. Surma and M. Świrkowicz (Institute of Electronic Materials Technology, Warsaw) for a fruitful discussions and for providing the crystals. We would like to thank J. Bondziul (Institute of Experimental Physics in University of Warsaw) for the technical assistance and for his excellent elaboration of experimental results.

\section{References}

[1] A.R. Lang, Acta Metall. 5, 358 (1957).

[2] A.R. Lang, J. Appl. Phys. 29, 597 (1958).

[3] A.R. Lang, J. Appl. Phys. 30, 1748 (1959).

[4] A.R. Lang, Acta Crystallogr. 12, 249 (1959).

[5] M. Lefeld-Sosnowska, in: Synchrotron Radiation Studies of Materials. Proc. of 5th $\mathrm{Na}$ tional Symposium of Synchrotron Radiation Users, Eds. J. Gronkowski, M. Lefeld-Sosnowska, Warsaw (Poland) 1999, p. 109.

[6] N. Kato, Acta Crystallogr. 14, 526 (1961).

[7] N. Kato, Acta Crystallogr. 14, 627 (1961).

[8] N. Kato, in: X-ray Diffraction, Eds. L.V. Azaroff, R. Kaplow, N. Kato, R.J. Weiss, A.J.C. Wilson, R.A. Young), McGrow-Hill, New York 1974, p. 176. 
[9] A. Authier, in: Adv. in X-ray Analysis 10, Eds. J.B. Newkirk, G.R. Mallett, Plenum Press, New York 1967, p. 9.

[10] A. Authier, in: Proc. Int. Summer School on X-ray Dynamical Theory and Topography, Limoges (France) 1975, (Univ. Pierre et Marie Curie, Paris 1975), Vol. A12, p. 1.

[11] A. Authier, Dynamical Theory of X-ray Diffraction, Oxford University Press Inc., New York 2001.

[12] P. Penning, D. Polder, Philips Res. Repts. 16, 419 (1961).

[13] C. Malgrange, in: Proc. Int. Summer School on $X$-ray Dynamical Theory and Topography, Limoges (France) 1975, (Univ. Pierre et Marie Curie, Paris 1975), Vol. A6, p. 1.

[14] N. Kato, J. Phys. Soc. Jpn. 18, 1785 (1963).

[15] N. Kato, J. Phys. Soc. Jpn. 19, 67 (1964).

[16] N. Kato, J. Phys. Soc. Jpn. 19, 971 (1964).

[17] S. Takagi, Acta Crystallogr. 15, 1311 (1962).

[18] S. Takagi, J. Phys. Soc. Jpn. 26, 1239 (1969).

[19] D. Taupin, Bull. Soc. Franç. Minér. Crist. 87, 469 (1964).

[20] M. Lefeld-Sosnowska, unpublished results (1978).

[21] M. Lefeld-Sosnowska, Phys. Status Solidi (a) 48, 565 (1978).

[22] A. Authier, M. Lefeld-Sosnowska, Y. Epelboin, A. Soyer, J. Appl. Crystallogr 18, 93 (1985).

[23] M. Lefeld-Sosnowska, Z. Grygoruk, K. Wokulska, J. Błażewicz, J. Phys. D, Appl. Phys. 34, A144 (2001).

[24] C.D. Brandle, J. Cryst. Growth 264, 593 (2004).

[25] A. Pajączkowska, A. Gloubokov, Prog. Cryst. Growth Charact. 36, 123 (1998).

[26] R. Uecker, P. Reiche, S. Ganschow, D.-C. Uecker, D. Schultze, Acta Phys. Pol. A 92, 23 (1997).

[27] K. Wieteska, W. Wierzchowski, W. Graeff, M. LefeldSosnowska, A. Pa jaczkowska, E. Wierzbicka, A. Malinowska, J. Alloys Compds. 401, 75 (2005).

[28] A. Malinowska, M. Lefeld-Sosnowska, A. Pajączkowska, A. Kłos, J. Cryst. Growth 290, 149 (2006).

[29] A. Malinowska, M. Lefeld-Sosnowska, K. Wieteska, W. Wierzchowski, A. Pajączkowska, W. Graeff, Acta Phys. Pol. A 114, 433 (2008).

[30] A. Malinowska, M. Lefeld-Sosnowska, K. Wieteska, W. Wierzchowski, J. Härtwig, W. Graeff, Phys. Status Solidi A 206/8, 1816 (2009).

[31] A. Malinowska, M. Lefeld-Sosnowska, J. Härtwig, J. Appl. Cryst. 46, 48 (2013).

[32] W. Wierzchowski, T. Balcer, K. Wieteska, A. Malinowska, M. Lefeld-Sosnowska, K. Mazur, HASYLAB Annual Report 2010, http://hasylab.desy. de/annual_report/files/2010/2010927.pdf .
[33] W. Wierzchowski, K. Wieteska, A. Malinowska, E. Wierzbicka, M. Lefeld-Sosnowska, M. Świrkowicz, T. Łukasiewicz, A. Pajączkowska, C. Paulmann, Acta Phys. Pol. A 124, 350 (2013).

[34] T. Balcer, W. Wierzchowski, K. Wieteska, Acta Phys. Pol. A 117, 336 (2010).

[35] A. Novoselov, G. Zimina, L. Komissarova, A. Pajączkowska, J. Cryst. Growth 287, 305 (2006).

[36] A. Malinowska, M. Lefeld-Sosnowska, K. Wieteska, W. Wierzchowski, W. Graeff, A. Pajączkowska, J. Cryst. Growth 310/14, 3398 (2008).

[37] A. Malinowska, M. Lefeld-Sosnowska, K. Wieteska, W. Wierzchowski, W. Graeff, A Pajączkowska, Synchrotron Radiation in Natural Science 7, 111 (2008).

[38] A. Malinowska, E. Wierzbicka, M. Lefeld-Sosnowska, K. Wieteska, W. Wierzchowski, T. Łukasiewicz, M. Świrkowicz, W. Graeff, Acta Phys. Pol. A 117, 328 (2010).

[39] K. Wieteska, W. Wierzchowski, E. Wierzbicka, A. Malinowska, M. Lefeld-Sosnowska, T. Łukasiewicz, W. Graeff, Acta Phys. Pol. A 114, 455 (2008).

[40] E. Wierzbicka, A. Malinowska, K. Wieteska, W. Wierzchowski, M. Lefeld-Sosnowska, M. Świrkowicz, T. Łukasiewicz, C. Paulmann, Acta Phys. Pol. A 121, 906 (2012).

[41] A. Borghesi, B. Pivac, A. Sasello, A. Stella, J. Appl. Phys. 77, 4169 (1995).

[42] J. Gronkowski, M. Lefeld-Sosnowska, E. ZielińskaRohozińska, Phys. Status Solidi A 29, 535 (1975).

[43] J. Jung, M. Lefeld-Sosnowska, Philos. Mag. A 50, 233 (1984).

[44] J. Jung, M. Lefeld -Sosnowska, in: Microstructural Characterisation of Materials by Non-Microscopical Techniques, Proc. 5th RISØ Intern. Symp. Metallurgy and Materials Science; Ed. N.H. Andersen, RIS $\varnothing$ National Laboratory, Roskilde (Denmark) 1984, p. 341.

[45] B.K. Tanner, X-ray Diffraction Topography, Pergamon, Oxford 1976.

[46] D.K. Bowen, B.K. Tanner, High resolution X-ray diffractometry and topography, London: Taylor \& Francis Ltd. (1998).

[47] M. Lefeld-Sosnowska, J. Gronkowski, G. Kowalski, J. Phys. D, Appl. Phys. 28, A42 (1995).

[48] J. Gronkowski, M. Lefeld-Sosnowska, E. ZielinskaRohozinska, J. Phys. D, Appl. Phys. 26, A62 (1993).

[49] G. Kowalski, M. Lefeld-Sosnowska, J. Gronkowski, J. Borowski, Philos. Trans. R. Soc. Lond. A 357, 2707 (1999).

[50] M. Lefeld-Sosnowska, phys. status solidi (a) 171, 105 (1999). 